PAPER

\title{
Intense T cell depletion followed by autologous bone marrow transplantation for severe multiple sclerosis
}

\author{
J P A Samijn, P A W te Boekhorst, T Mondria, P A van Doorn, H Z Flach, F G A van der Meché, \\ J Cornelissen, W C Hop, B Löwenberg, R Q Hintzen
}

J Neurol Neurosurg Psychiatry 2006;77:46-50. doi: 10.1136/jnnp.2005.063883

See end of article for authors' affiliations

.....................

Correspondence to: Dr R Q Hintzen,

Department of Neurology, MS Centre ErasMS,

Erasmus MC, Postbox

2040,3000 CA

Rotterdam, The

Netherlands; rhintzen@

xs4all.nl

Received 20 January 2005

Revised form received

12 April 2005

Accepted 29 April 2005

\begin{abstract}
Background: Certain stem cell transplantation procedures might slow down inflammatory pathology in multiple sclerosis (MS).

Aims: To halt disease progression in aggressive MS by a bone marrow transplantation (BMT) protocol aimed at maximum $T$ cell suppression.

Methods: Autologous BMT was performed in 14 patients with rapid secondary progressive MS (median EDSS score at baseline, 6; median disease duration, five years). To accomplish rigorous $T$ cell ablation, a strong conditioning protocol was chosen-cyclophosphamide, total body irradiation, and antithymocyte globulin. To minimise the possibility of reinfusing mature T cells in the graft, bone marrow, not peripheral blood, was used as the CD34+ stem cell source.

Results: Median follow up was 36 months (range, 7-36). Post-transplant haemopoietic recovery was successful in all patients. Early toxicity included Epstein-Barr virus related post-transplantation lymphoproliferative disorder. Longterm effects were development of antithyroid antibodies (three) and myelodysplastic syndrome (one). One patient died of progressive disease five years after transplantation. Treatment failure, defined by EDSS increase sustained for six months or more, was seen in nine patients and stabilisation or improvement in five. Other clinical parameters generally showed the same outcome. No gadolinium enhanced lesions were seen on post-treatment magnetic resonance imaging, in either cerebral or spinal cord scans. However, cerebrospinal fluid oligoclonal bands remained positive in most cases.

Conclusions: This strong immunosuppressive regimen did not prevent clinical progression in patients with aggressive secondary MS. The lack of efficacy, together with some serious side effects, does not favour the use of similar rigorous $T$ cell depleting protocols in the future.
\end{abstract}

l most models of the aetiopathogenesis of multiple sclerosis (MS), there is a central role for autoreactive $\mathrm{T}$ cells. ${ }^{1}$ This has led to the development of treatments that suppress the activation of T cells and other components of the immune system. However, none of these strategies has proved sufficiently powerful. ${ }^{2}$ At the start of our study, evidence had been obtained (animal models, case reports, and clinical studies) that high dose immunosuppression followed by stem cell transplantation could help control the disease. ${ }^{3-6}$ Subsequently, several groups in Europe and the USA have embarked on treatment protocols with marrow ablation, followed by stem cell rescue. ${ }^{7-10}$ The protocols that were used in the different studies were heterogeneous. ${ }^{11-13}$ Even within individual studies diverse protocols have been applied. A common denominator of most studies has been the use of peripheral blood stem cells for grafting. These cells can be easily obtained from the patient after leucapheresis, obviating the need for anaesthesia. In our study, we investigated the effects and side effects of stem cell transplantation using a protocol that aimed at maximal $\mathrm{T}$ cell depletion. To minimise the possibility of reinfusing potentially harmful autoreactive $\mathrm{T}$ cells, we chose to use bone marrow instead of peripheral blood as the source of stem cells. In addition, we applied antithymocyte globulin (ATG) for in vivo elimination of residual T cells and we used CD34 purified stem cells for in vitro depletion of the haemopoietic graft. Only patients with secondary progressive disease who had the ability to walk but had a rapidly deteriorating course were eligible for the protocol.

\section{METHODS}

\section{Patient selection}

Patients were considered for inclusion if MS had been diagnosed using Poser's criteria. Inclusion criteria were: age between 18 and 50 years, EDSS between 5.0 and 7.0 (7 excluded), EDSS of at least 3.0 two years after diagnosis, EDSS increase of $\geqslant 1.0$ in the previous two years if EDSS $\geqslant 5.5$ or of $\geqslant 1.5$ if EDSS was 5.0. ${ }^{14}$ All subjects had to have good pulmonary, hepatic, and renal function, good general and mental health, and a negative human immunodeficiency virus status. Patients with primary progressive MS were excluded. Two neurologists and one haematologist screened all included patients. Fewer than $5 \%$ of the patients referred to us met the selection criteria. Transplantations were performed between September 1998 and December 2003. The local medical ethical committee had approved the study and written informed consent was acquired. During the pretransplantation period all immunomodulating drugs were discontinued at least one month in advance. To ensure a stable baseline, bone marrow transplantation (BMT) was postponed for at least two months in case of a relapse.

\section{Haemopoietic stem cell procurement}

Bone marrow was aspirated from the posterior iliac crest during general anaesthesia. CD34+ stem cells were selected

Abbreviations: ATG, antithymocyte globulin; BMT, bone marrow transplantation; CSF, cerebrospinal fluid; MRI, magnetic resonance imaging; MS, multiple sclerosis 
using a CellPro column (CellPro Inc, Bothell, Washington, USA) in the first three patients, and a Clinimax column (Miltenyi Biotech, Amsterdam, the Netherlands) in all others. A minimum yield of $1.0 \times 10^{6} \mathrm{CD} 34+$ cells $/ \mathrm{kg}$ body weight was obtained in 13 of the 14 patients (range, $1.14-2.72 \times 10^{6} / \mathrm{kg}$ ). In one patient, a low yield of $0.28 \times 10^{6} \mathrm{CD} 34+$ cells $/ \mathrm{kg}$ necessitated a supplementary harvest of stem cells by pheresis from peripheral blood. Granulocyte colony stimulating factor $(5 \mu \mathrm{g} /$ kg subcutaneously, twice daily) was given and additional stem cells were collected. CD34+ cells were cryopreserved in liquid nitrogen using standard techniques.

\section{Conditioning regimen and supportive care}

The conditioning regimen consisted of ATG (lymphoglobulin, horse serum; Mérieux, Marcy l'Etoile, France) at a dose of $15 \mathrm{mg} / \mathrm{kg}$ intravenously from days -7 to -3 . On days -4 and -3 , cyclophosphamide was added at a dose of $60 \mathrm{mg} / \mathrm{kg}$ intravenously, combined with mesnum $(15 \mathrm{mg} / \mathrm{kg}$, four times each day). Total body irradiation was given in two fractions of $5 \mathrm{~Gy}$, at day -2 and -1 . On day 0 , the autologous graft was thawed and reinfused using a central venous catheter. To prevent serum sickness, prednisolone ( $1 \mathrm{mg} / \mathrm{kg}$ twice daily) was given concurrently, and tapered after stem cell reinfusion. Supportive care included pre-irradiated prophylactic platelet and red blood cell transfusions when necessary. Patients were discharged from the haematology ward after granulocyte and platelet repopulation. To prevent infections with Pneumocystis carinii, cotrimoxazol treatment was given for six months.

\section{Outcome measures}

The primary aim of the treatment was to prevent disease progression and further loss of neurological function. Treatment failure was defined as disease progression from the pretransplantation EDSS of at least 1.0 EDSS point (for baseline EDSS 5.0 and 5.5) or 0.5 point (for baseline EDSS above 5.5), sustained for more than six months after transplantation, with no other explanation for change in function.

Secondary outcome measures were Scripps neurological rating scale (range, $0-100$; a 10 point difference is generally considered to be a relevant change, lower scores indicating more deficit), ambulation index (range, 0-9), and the nine hole peg test (in seconds, a $20 \%$ difference is generally considered to be a relevant change). When a spinal tap was allowed, cerebrospinal fluid (CSF) was tested for oligoclonal bands. MS exacerbations were defined as new or re-occurring neurological deterioration lasting for more than 48 hours in the absence of fever or illness, and with objective neurological changes on examination.

\section{Magnetic resonance imaging}

Brain magnetic resonance imaging (MRI) scans were performed at every visit with an extra measurement three months before BMT. Spinal cord MRI was done yearly. A 1.5 Tesla scanner (Philips) was used and slices were made every $5 \mathrm{~mm}$ without intergap spaces. Gadolinium pentate (0.1 mmol/litre) enhanced $\mathrm{Tl}$ weighted images were made at each visit. To improve sensitivity, the gadolinium dose was increased to triple the previous dose in April 2000 (0.3 mmol/ $\mathrm{kg}$ ), after inclusion of patient number 6 . The triple dose was used in all further scans (including follow up scans of patients $1-5)$.

\section{RESULTS}

Table 1 summarises the clinical characteristics of the 14 patients; eight were female.

The median age was 35 years (range, 23-50). In line with the inclusion criteria, all patients had accumulated considerable disability over a short period of time before transplantation. The median duration of antecedent disease was five years (range, two to 12) and the median EDSS score at baseline was 6 (range, 5 to 6.5). Nine of the 14 patients had suffered from one or more relapse in the year before BMT and all had secondary progressive MS. In the post-transplantation period, patients were followed for up to 36 months (median post-transplantation follow up, 36 months; range, seven to 36).

\section{Toxicity}

Common side effects were mucositis $(\mathrm{n}=10)$, skin rash $(\mathrm{n}=6)$, alopecia (all), and general fatigue (all). Fever during granulocytopenia was seen in five patients. Clostridium difficile gastroenteritis occurred in two patients within the first eight weeks after BMT, in both cases successfully treated with metronidazol. Except for one herpes zoster infection, no late infectious complications occurred. One patient who had had a minor head trauma developed signs of intracranial hypotension as a result of nasal CSF leakage at nine months after transplantation. The fistula was closed neurosurgically. One male and one female patient developed autoimmune thyroiditis leading to hypothyroid function. One of them (patient 4) had coexisting type I diabetes mellitus. Both patients developed serum antibodies against thyroid stimulating hormone receptor and antithyreoglobulin. An additional male patient developed antithyroid antibodies (patient 1), until now without clinical or laboratory signs of thyroid dysfunction. One patient (patient 13) developed Epstein-Barr virus associated lymphoproliferative disease, which was effectively treated with a single gift of anti-CD20 antibody

Table 1 Baseline characteristics of the 14 patients

\begin{tabular}{|c|c|c|c|c|c|c|c|c|}
\hline Patient & Age & Sex & MS duration (years) & Relapses* & EDSS & Al & SNRS & Previous treatment \\
\hline 1 & 31 & $M$ & 5 & 2 & 6 & 4 & 67 & $\mathrm{IFN} \beta$ \\
\hline 2 & 39 & $M$ & 4 & 1 & 6.5 & 5 & 59 & - \\
\hline 3 & 48 & $\mathrm{~F}$ & 5 & 1 & 6.5 & 6 & 55 & - \\
\hline 4 & 47 & $M$ & 5 & 0 & 6.5 & 4 & 56 & - \\
\hline 5 & 44 & $\mathrm{~F}$ & 4 & 5 & 6.5 & 6 & 66 & $\mathrm{IFN} \beta$ \\
\hline 6 & 31 & $\mathrm{~F}$ & 5 & 3 & 5.5 & 4 & 62 & IFN $\beta$ \\
\hline 7 & 37 & $\mathrm{~F}$ & 5 & 0 & 6 & 4 & 67 & - \\
\hline 8 & 50 & $\mathrm{~F}$ & 4 & 0 & 5.5 & 3 & 77 & - \\
\hline 9 & 41 & $\mathrm{~F}$ & 2 & 1 & 6 & 6 & 76 & IFN $\beta+$ IVIG \\
\hline 10 & 23 & $M$ & 6 & 2 & 6 & 5 & 64 & IFN $\beta+$ IVIG \\
\hline 11 & 34 & $\mathrm{~F}$ & 3 & 1 & 5 & 3 & 66 & IFN $\beta$ \\
\hline 12 & 34 & $M$ & 12 & 1 & 6 & 4 & 51 & $\mathrm{IFN} \beta$ \\
\hline 13 & 32 & $M$ & 8 & 2 & 6 & 4 & 76 & IFN $\beta$ \\
\hline 14 & 35 & $\mathrm{~F}$ & 6 & 0 & 6.5 & 6 & 67 & IFN $\beta$ \\
\hline
\end{tabular}

The duration of MS was counted from the second demyelinating event, usually time of diagnosis.

*Total number in the preceding year.

$\mathrm{Al}$, ambulation index; INF $\beta$, interferon $\beta 1 \mathrm{a}$ or $\beta 1 \mathrm{~b}$; IVIG, intravenous immunoglobulin; MP, methylprednisolone; MS, multiple sclerosis; SNRS, Scripps neurological rating scale. 
(Rituximab, $375 \mathrm{mg} / \mathrm{m}^{2}$ ) (unpublished data, 2002). At five years after transplantation, one female patient (patient 7) developed a myelodysplastic syndrome, which currently requires treatment. Finally, one patient (patient 3 ) died five years after BMT from a respiratory infection related to the progression of disability.

\section{Neurological toxicity}

In the first week after engraftment, loss of dexterity and general muscular weakness were noted in all patients, attributed to a combination of immobilisation, anaemia, and fever.

One patient developed weakness and paraesthesia of all limbs after the first dose of ATG, which lasted several hours and resembled the transient motor dysfunction described after CAMPATH infusion. ${ }^{15}$ A confusional state resolving within a few hours was seen in two patients after administration of ATG. Two patients clearly developed increased lower limb paresis within two weeks after conditioning. In these cases the paresis was persistent, permanently affecting the EDSS scores. Ten patients complained of moderate to severe muscle spasms, most prominent during the first six months after BMT. They were successfully treated with baclofen. Two patients developed decreased visual function within one month and two others at six and 18 months after BMT. In only one of these four patients there was a typical pattern of optic neuritis, unilateral with rapid and partial recovery within a few weeks. Bilateral loss of visual acuity over months was measured in the other three patients.

\section{Clinical outcome measures}

After the median follow up of 36 months, nine patients had an EDSS increase that was sustained for over six months (at least 1.0 EDSS point for baseline EDSS 5.0 and 5.5, and 0.5 point for baseline EDSS above 5.5) (table 2). Six of these nine patients lost their ability to walk (EDSS 7.0 or more). EDSS improvement was seen in two patients and three patients stabilised at their pretransplant EDSS score. Of the nine patients who deteriorated, seven became worse within the first six months and all within the first nine months after transplantation (fig 1). After reaching the milestone of sustained EDSS 0.5 decline over six months, seven of these nine worsening patients continued to decline in the total 36 months of follow up.

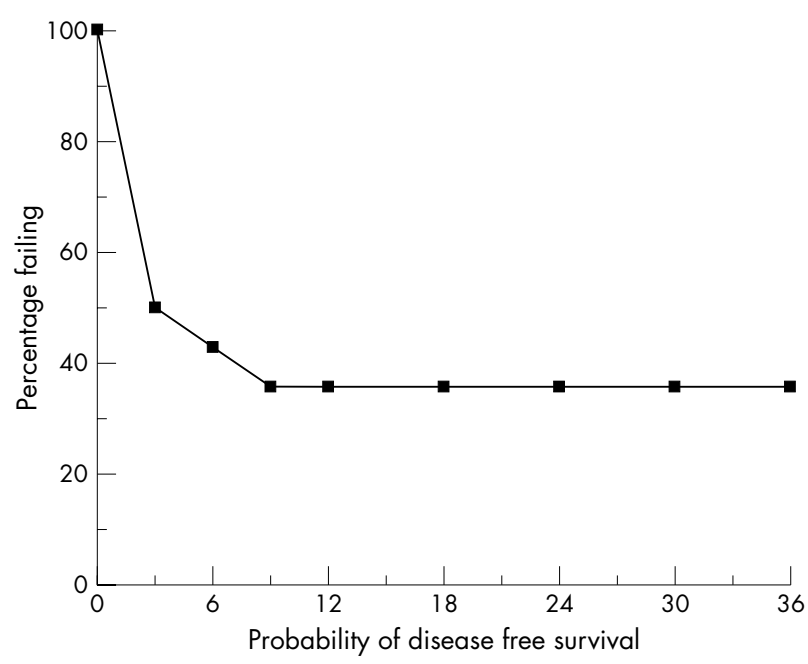

Figure 1 Actuarial probability of progression free survival (no rise in EDSS for six months or longer) in 14 patients with multiple sclerosis. The $y$ axis is the percentage failing by at least 1.0 EDSS point for baseline EDSS 5.0 and 5.5 , or 0.5 point for baseline EDSS above 5.5.
Ambulation index scores improved in two (lower score), remained stable in two, and worsened in 10 patients. Scripps neurological rating scale scores were improved in four and worse in 10 patients. The nine hole peg test sum score (right arm in/right arm out/left arm in/left arm out) had a mean value of 89.3 seconds at baseline compared with 120.1 seconds at the last available follow up. The nine hole peg test sum score improved in two patients, four were stable, and eight had worse scores (available in 13 patients only).

A clear exacerbation was seen in five patients, all characterised by a sudden deterioration in association with at least one point decline in EDSS. Improvements were seen after at least three weeks post-onset. No relapses were seen in the nine patients who did not progress.

\section{Magnetic resonance imaging}

Gadolinium enhanced lesions at baseline were seen in seven of the 14 patients and on 12 of 29 baseline scans. A maximum of two lesions was seen on these scans.

Post-BMT scans were performed at the predefined intervals as indicated above. In total, 124 brain MRI scans of all 14 participants were evaluated for new or persisting gadolinium enhanced lesions. There was a complete absence of gadolinium enhanced lesions on these scans. In addition, 53 spinal cord MRI scans of all 14 participants showed no enhanced lesions after BMT.

\section{DISCUSSION}

In our study, we applied a treatment protocol with the aim of establishing rigorous $\mathrm{T}$ cell ablation. This procedure differed from protocols applied in other studies ${ }^{16-18}$ by the inclusion of total body irradiation and the use of purified bone marrow derived CD34+ stem cells, in combination with high dose cyclophosphamide and administration of ATG. The primary goal of this treatment was to halt disease progression. We specifically selected patients with MS who had strongly progressive secondary disease and paid special attention to the selection of patients with relatively high current disease activity by introducing an extra criterion of EDSS at least 3.0 two years after diagnosis. ${ }^{19}$ In addition, we only recruited patients with the ability to walk (EDSS below 7.0). Therefore, our study group did not contain patients in the very high EDSS range and was relatively more homogeneous than most other studies on the effect of stem cell transplantation in MS. $^{20}{ }^{21}$ The treatment target was stabilisation or improvement of disability, rated according to EDSS scores. Of the 14 patients studied, nine reached the level of treatment failure, defined as rise in EDSS score of 0.5 or more, sustained for at least six months. It is highly unlikely that in this set of patients with secondary progressive disease the EDSS changes would revert to lower levels after further follow up. The duration of MS, baseline EDSS, and the number of relapses one year before baseline did not correlate with outcome, but numbers are small and the baseline characteristics were very similar.

Because systematic neurological follow up was limited to three years post-transplantation, any stabilisation after this period cannot be fully excluded. However, the fact that seven of the nine initially worsening patients also deteriorated beyond the first year does not suggest later clinical benefit. Although we cannot be certain about the natural rate of progression of individuals in this heterogeneous disease, the rapid and sustained decline seen here is not encouraging. Natural history data have shown that patients with MS, once they reach EDSS 6, stay at this level for an average of 4.24 years. $^{7}$ Thus, it is striking that in our study, nine of the 14 patients who only recently reached a median EDSS of 6, progressed within nine months. In theory, this rapid deterioration shortly after treatment could be related to the 


\begin{tabular}{|c|c|c|c|c|c|c|c|c|}
\hline Patient & $\begin{array}{l}\mathrm{F} / \mathrm{U} \\
\text { (months) }\end{array}$ & $\begin{array}{l}\text { Exacerbations } \\
\text { post-BMT}\end{array}$ & $\Delta$ EDSS† & $\Delta$ Alł & $\Delta$ SNRS $\S$ & $\begin{array}{l}\Delta \text { 9-HPT } \\
(\%)\end{array}$ & $\begin{array}{l}\text { Oligoclonal } \\
\text { bands b/a }\end{array}$ & Complications \\
\hline 1 & 36 & 1 & 2 & 5 & -23 & 64 & $-1-$ & Antithyroid antibodies \\
\hline 2 & 36 & 1 & 1.5 & 4 & -13 & 78 & NA & \\
\hline 3 & 36 & 1 & 1.5 & 3 & -15 & 71 & $+/+$ & $\begin{array}{l}\text { Died } 5 \text { years after } \\
\text { BMT }\end{array}$ \\
\hline 4 & 36 & 0 & 0 & 2 & 4 & 23 & $-/ N A$ & $\begin{array}{l}\text { Autoimmune } \\
\text { thyroiditis }\end{array}$ \\
\hline 5 & 36 & 4 & 1.5 & 3 & -21 & 13 & NA & \\
\hline 6 & 36 & 0 & -1.0 & -1 & 10 & -36 & $-1-$ & \\
\hline 7 & 36 & 0 & -0.5 & 0 & 1 & -53 & NA & $\begin{array}{l}\text { Myelodysplastic } \\
\text { syndrome }\end{array}$ \\
\hline 8 & 36 & 0 & 1 & 3 & -18 & 34 & NA & \\
\hline 9 & 30 & 0 & 0 & -1 & -7 & 3 & $+/-$ & CSF leakage \\
\hline 10 & 24 & 1 & 2 & 4 & -15 & 187 & $+/+$ & \\
\hline 11 & 24 & 0 & 1.5 & 3 & -2 & 47 & $+/+$ & \\
\hline 12 & 24 & 0 & 0.5 & 2 & -10 & 67 & $-/ N A$ & \\
\hline 13 & 12 & 0 & 0 & 0 & 6 & -2 & $+/+$ & EBV-PTLD \\
\hline 14 & 7 & 0 & 0.5 & 1 & -11 & 114 & $+/+$ & $\begin{array}{l}\text { Autoimmune } \\
\text { thyroiditis }\end{array}$ \\
\hline \multicolumn{9}{|c|}{$\begin{array}{l}\text { Al, ambulation index; b/a, before/after BMT; EBV-PTLD, Epstein-Barr virus related post-transplantation lymphoproliferative disorder; F/U, follow up; } 9-\mathrm{HPT} \text {, nine } \\
\text { hole peg test; NA, not allowed; SNRS, Scrips neurological rating scale. } \\
\text { "Total number of exacerbations during follow up; †EDSS: 0-10, positive } \Delta \text { scores indicate worsening, comparing baseline with last observation during follow up, } \\
\text { sustained for } 6 \text { months; } ¥ \text { SNRS: 0-100, positive } \Delta \text { scores indicate improvement; §Al: } 0-9 \text {, positive } \Delta \text { scores indicate worsening; } \uparrow 9-H P T: \% \text { reduction in seconds, } \\
\text { positive } \Delta \text { scores indicate worsening. }\end{array}$} \\
\hline
\end{tabular}

special emphasis on recruitment of patients with highly active disease. Pathological processes present before conditioning could have delayed effects on neurological function over months, even in the case of a successful treatment effect on inflammation, or in the case of natural regression of inflammatory activity. ${ }^{22}$ In contrast, in most MS trials it is much more common to see the opposite phenomenon, patients remaining stable or improving after inclusion (regression to the mean). Other studies on stem cell transplantation in MS, using milder immunosuppressive protocols, but also selecting patients with aggressive MS, have generally shown better results. Despite the fact that none of the studies to date has been performed in a controlled fashion, it is worth considering the possible influence of different treatment regimens. The question arises as to whether the rapid progression seen in our study could be related to the neurotoxicity of the procedure itself. This would be compatible with the clinical course seen directly after conditioning in most patients-a subacute deterioration over weeks or months, without overt exacerbation activity at this stage. In another study on stem cell transplantation in MS that also included total body irradiation in the conditioning scheme, ${ }^{20}$ it has been suggested that radiotherapy (perhaps in combination with cyclophosphamide) could lead to increased axonal damage, especially in patients with MS who have a more progressive form of the disease. However, this is a controversial viewpoint, which is supported by some indirect evidence. In some studies on experimental autoimmune encephalomyelitis, total body irradiation induced or facilitated short term neurological worsening. ${ }^{23-25}$ In addition, in several patients with demyelinating disease, a severe clinical course has been noted after cranial irradiation. ${ }^{26}$ A biological explanation for the negative effect of irradiation has at least been partly provided by studies showing neural precursor cell dysfunction, together with pronounced microglia activation, after cranial irradiation. ${ }^{27}$

Another specific characteristic of our treatment regimen has been the emphasis on extreme lymphocyte depletion. There is one study in rheumatoid arthritis that compared treatment effects after infusion with CD34+ selected versus unmanipulated autologous stem cells. ${ }^{28}$ The authors concluded that this expensive $\mathrm{T}$ cell depleting procedure provided no extra benefit, and it may have increased the potential for opportunistic infections. Recent insight suggests that infusion with unmanipulated stem cell grafts may even be preferable because these may contain important regulatory $\mathrm{T}$ cell subsets (including CD4+ CD25+ cells and natural killer cell subsets), in addition to early CD34 negative stem cells, which may have considerable (neuro)regenerative capacity. ${ }^{29-31}$

Apart from these considerations on clinical neurological effects seen in the first nine months after transplantation, has our protocol succeeded at all in achieving a profound longterm suppression of inflammatory activity in the central nervous system? At first sight, the lack of enhancement on the cerebral and spinal cord MRIs obtained after transplantation provides evidence of an anti-inflammatory effect. ${ }^{32}$ However, this effect was not complete because previous disability worsened in one patient, and new signs and symptoms occurred in another four. Because exacerbations are thought to be the clinical reflection of inflammatory activity, the observed relapses suggest that there can still be disease activity behind a largely intact blood brain barrier, as observed in other studies. ${ }^{33}{ }^{34}$ Furthermore, pre-existing CSF oligoclonal bands were still seen after transplantation in five of the six patients who tested positive before transplantation. Others have also observed this in non-total body irradiation based protocols. ${ }^{35}$

A considerable part of the progression seen was independent of exacerbations, persisted during longterm follow up over three years and, as mentioned above, occurred in the absence of brain or spinal cord gadolinium enhancement. Irrespective of the treatment regimen used, similar clinical signs of presumed persistent neurodegeneration have also been reported in other studies. ${ }^{18} 2036$ Perhaps profound suppression of inflammation has no beneficial effect on the progression of disability once the damage is beyond a certain limit of neuronal repair. ${ }^{37}$ This is not without precedence, as shown in CAMPATH and Cladribine studies. ${ }^{22}{ }^{38}$ Interestingly, the visual symptoms seen in three patients were also more typical of slowly progressive optic neuropathy than of acute optic neuritis. Overall, it is possible that better results would have been obtained when using this treatment protocol for patients with relapsing remitting MS at an earlier stage of the disease.

Our study shows that a maximum intensive immunosuppressive protocol is associated with serious non-neurological complications. A severe threat was an Epstein-Barr virus 
related lymphoproliferative disease, a potentially lethal complication related to strong immunosuppression. Similar complications have also been reported in other studies. ${ }^{21}$ In another patient, with clear neurological improvement after transplantation, a myelodysplastic syndrome developed five years after transplantation. This haematological disorder is a known possible sequel that can occur years after BMT. ${ }^{39}$ A novel finding is the development of thyroid autoimmunity in three of the 14 patients, in two cases associated with clinically manifest disease. This is reminiscent of the thyroid autoimmunity seen after CAMPATH treatment. ${ }^{15}$ This phenomenon may be related rather to strong forms of immunosuppression in general than to transplantation per se, perhaps as a result of depleting beneficial CD4+ CD25+ regulatory $\mathrm{T}$ cells. It is of note that the development of humoral autoimmunity after autologous transplantation has also been reported in other conditions. ${ }^{40}{ }^{41}$

In conclusion, this extremely immunosuppressive protocol did not prevent clinical progression in a selected group of patients with aggressive secondary MS. The lack of efficacy in this uncontrolled study, together with some serious side effects, does not favour the use of similar rigorous protocols in the future.

\section{ACKNOWLEDGEMENTS}

The Dutch MS Research Foundation and Erasmus MC, Rotterdam supported this study. We wish to thank Professor F Barkhof for his expert advice on MRI.

\section{Authors' affiliations}

J P A Samijn, T Mondria, P A van Doorn, F G A van der Meché,

R Q Hintzen, Department of Neurology, Erasmus Medical Centre Rotterdam, Postbox 2040, 3000 CA Rotterdam, The Netherlands P A W te Boekhorst, J Cornelissen, B Löwenberg, Department of Haematology, Erasmus Medical Centre Rotterdam

H Z Flach, Department of Radiology, Erasmus Medical Centre Rotterdam W C Hop, Department of Biostatistics, Erasmus Medical Centre Rotterdam

Competing interests: none declared

\section{REFERENCES}

1 Compston A, Coles AJ. Multiple sclerosis. Lancet 2002;359:1221-31.

2 Noseworthy JH, Lucchinetti C, Rodriguez M, et al. Multiple sclerosis. N Engl J Med 2000;343:938-52.

3 van Gelder M, van Bekkum DW. Effective treatment of relapsing experimental autoimmune encephalomyelitis with pseudoautologous bone marrow transplantation. Bone Marrow Transplant 1996;18:1029-34.

4 Karussis DM, Vourka-Karussis U, Lehmann D, et al. Prevention and reversal of adoptively transferred, chronic relapsing EAE with a single high dose cytoreductive treatment followed by syngeneic bone marrow transplantation. J Clin Invest 1993;92:765-72.

5 McAllister LD, Beatty PG, Rose J. Allogeneic bone marrow transplant for chronic myelogenous leukemia in a patient with multiple sclerosis. Bone Marrow Transplant 1997;19:395-7.

6 Fassas A, Anagnostopoulos A, Kazis A, et al. Peripheral blood stem cell transplantation in the treatment of progressive multiple sclerosis: first results of a pilot study. Bone Marrow Transplant 1997;20:631-8.

7 Mandalfino $P$, Rice $G$, Smith A, et al. Bone marrow transplantation in multiple sclerosis. J Neurol 2000;247:691-5.

8 Burt RK, Burns WH, Miller SD. Bone marrow transplantation for multiple sclerosis: returning to Pandora's box. Trends Immunol Today 1997; 18:559-61.

9 Burt RK, Traynor AE, Pope R, et al. Treatment of autoimmune disease by intense immunosuppressive conditioning and autologous hematopoietic stem cell transplantation. Blood 1998;10:3505-14.

10 Kozák T, Havrdova E, Pit'ha J, et al. High-dose immunosuppressive therapy with PBSC support in the treatment of poor risk multiple sclerosis. Bone Marrow Transplant 2000;25:525-31.

11 Hintzen RQ. Stem cell transplantation in multiple sclerosis: multiple choices and multiple challenges. Multiple Sclerosis 2002;8:155-60.

12 Fassas A, Passweg JR, Anagnostopoulos A, et al. Autoimmune disease working party of the EBMT (European group for blood and marrow transplantation). Hematopoietic stem cell transplantation for multiple sclerosis. A retrospective multicenter study. J Neurol 2002;249:1088-97; editorial, $1147-9$.

13 Blanco Y, Saiz A, Carreras E, et al. Autologous haematopoietic-stem-cell transplantation for multiple sclerosis. Lancet Neurol 2005;4:54-63.

14 Comi G, Kappos L, Clanet M, et al. Guidelines for autologous blood and marrow stem cell transplantation in multiple sclerosis: a consensus report written on behalf of the European group for blood and marrow transplantation and the European Charcot Foundation. J Neurol 2000;247:376-82

15 Coles AJ, Wing M, Smith S, et al. Pulsed monoclonal antibody treatment and autoimmune thyroid disease in multiple sclerosis. Lancet 1999;354:1691-5.

16 Fassas A, Anagnostopoulos A, Kazis A, et al. Autologous stem cell transplantation in progressive multiple sclerosis - an interim analysis of efficacy. J Clin Immunol 2000;20:24-30.

17 Mancardi GL, Saccardi R, Filippi M, et al. Autologous hematopoietic stem cell transplantation suppresses Gd-enhanced MRI activity in MS. Neurology 2001;57:62-8.

18 Saiz A, Blanco Y, Carreras E, et al. Clinical and MRI outcome after autologous hematopoietic stem cell transplantation in MS. Neurology 2004;62:282-4.

19 Weinshenker BG, Bass B, Rice GP, et al. The natural history of multiple sclerosis: a geographically based study. 1. Clinical course and disability. Brain 1989;112:133-46.

20 Burt RK, Cohen BA, Russell E, et al. Hematopoetic stem cell transplantation for progressive multiple sclerosis: failure of a total body irradiation-based conditioning regimen to prevent disease progression in patients with high disability scores. Blood 2003;102:2373-8.

21 Nash RA, Bowen JD, McSweeney PA, et al. High-dose immunosuppressive therapy and autologous peripheral blood stem cell transplantation for severe multiple sclerosis. Blood 2003; 102:2364-72.

22 Coles AJ, Wing MC, Molyneux $\mathrm{P}$, et al. Monoclonal antibody treatment exposes three mechanisms underlying the clinical course of multiple sclerosis. Ann Neurol 1999;46:296-304.

23 Eralinna JP, Soilu-Hanninen $M$, Roytta $M$, et al. Facilitation of experimental allergic encephalomyelitis by irradiation and virus infection: role of inflammatory cells. J Neuroimmunol 1994;55:81-90.

24 van Gelder M, Kinwel-Bohre EP, van Bekkum DW. Treatment of experimental allergic encephalomyelitis in rats with total body irradiation and syngeneic BMT. Bone Marrow Transplant 1993;1 1:233-41.

25 van Gelder $M$, van Bekkum DW. Treatment of relapsing experimental autoimmune encephalomyelitis in rats with allogeneic bone marrow transplantation from a resistant strain. Bone Marrow Transplant 1995; 16:43-51.

26 Murphy CB, Hashimoto SA, Graeb D, et al. Clinical exacerbation of multiple sclerosis following radiotherapy. Arch Neurol 2003;60:273-5.

27 Monje ML, Mizumatsu S, Fike JR, et al. Irradiation induces neural precursorcell dysfunction. Nat Med 2002;8:955-62.

28 Moore J, Brooks $\mathrm{P}$, Milliken S, et al. A pilot randomized trial comparing CD34-selected versus unmanipulated hemopoietic stem cell transplantation for severe, refractory rheumatoid arthritis. Arthritis Rheum 2002;46:2301-9.

29 Brenner MK. Haematopoietic stem cell transplantation for autoimmune disease: limits and future potential. Best Pract Res Clin Haematol 2004; 17:359-74.

30 Dezawa $M$, Kanno $H$, Hoshino $M$, et al. Specific induction of neuronal cells from bone marrow stromal cells and application for autologous transplantation. J Clin Invest 2004;113:1701-10

31 Guo Y, Lubbert M, Engelhardt M. CD34- hematopoietic stem cells: current concepts and controversies. Stem Cells 2003;21:15-20.

32 Koudriavtseva T, Thompson A, Fiorelli M, et al. Gadolinium enhanced MRI predicts clinical and MRI disease activity in relapsing remitting MS. J Neurol Neurosurg Psychiatry 1997;62:285-7.

33 Buljevac D, Flach HZ, Hop WC, et al. Prospective study on the relationship between infections and multiple sclerosis exacerbations. Brain 2002; 125:952-60.

34 Kappos L, Moeri D, Radue EW, et al. Predictive value of gadoliniumenhanced magnetic resonance imaging for relapse rate and changes in disability or impairment in MS: a meta-analysis. Lancet 1999;353:964-9.

35 Saiz A, Carreras E, Berenguer J, et al. MRI and CSF oligoclonal bands after autologous stem cell transplantation in MS. Neurology 2001;56:1084-9.

36 Fassas A, Nash R. Stem cell transplantation for autoimmune disorders. Multiple sclerosis. Best Pract Res Clin Haematol 2004;17:247-62.

37 Trapp BD, Ransohoff R, Rudick R. Axonal pathology in multiple sclerosis: relationship to neurologic disability. Curr Opin Neurol 1999;12:295-302.

38 Beutler E, Sipe JC, Romine JS, et al. The treatment of chronic progressive multiple sclerosis with cladribine. Proc Natl Acad Sci U S A 1996;93:1716-20.

39 Matayer C, Curtis RE, Vose J, et al. Myelodysplastic syndrome and acute leukemia after autotransplantation for lymphoma: a multicenter case-control study. Blood 2003;101:2015-23.

40 Ishikawa F, Shigematsu H, Gondo H, et al. Autoreactive antibodies following autologous peripheral blood stem cell transplantation. Bone Marrow Transplant 1998;22:729-31

41 Hequet $\mathrm{O}$, Salles $\mathrm{G}$, Ketterer N, et al. Autoimmune thrombocytopenic purpura after autologous stem cell transplantation. Bone Marrow Transplant 2003;32:89-95. 